\title{
Morphological alterations of the pyramidal and stellate cells of the visual cortex in schizophrenia
}

\author{
IOANNIS MAVROUDIS ${ }^{1-3}$, FOIVOS PETRIDES ${ }^{1,4}$, DIMITRIOS KAZIS ${ }^{4}$, SYMELA CHATZIKONSTANTINOU ${ }^{4}$, \\ ELENI KARANTALI ${ }^{4}$, ALIN CIOBICA ${ }^{5-7}$, ALIN-CONSTANTIN IORDACHE ${ }^{8}$, ROMEO DOBRIN $^{8}$, \\ CONSTANTIN TRUS $^{9}$, SAMUEL NJAU ${ }^{10}$, VASILIKI COSTA ${ }^{1,3}$ and STAVROS BALOYANNIS ${ }^{1,3}$
}

${ }^{1}$ Laboratory of Neuropathology and Electron Microscopy First Department of Neurology, Aristotle University of Thessaloniki, Thessaloniki 54634, Greece; ${ }^{2}$ Department of Neurology, Leeds Teaching Hospitals, Leeds LS1 3EX, UK;

${ }^{3}$ Institute For Research Of Alzheimer's Disease, Other Neurodegenerative Diseases And Normal Aging, Heraklion Langada 57200; ${ }^{4}$ Third Department of Neurology, Aristotle University of Thessaloniki, Thessaloniki 57010, Greece;

${ }^{5}$ Department of Biology, Faculty of Biology, Alexandru Ioan Cuza University, Iasi 700506;

${ }^{6}$ Academy of Romanian Scientists, Bucuresti 050094; ${ }^{7}$ Center of Biomedical Research, Romanian Academy, Iasi 700506;

${ }^{8}$ Faculty of Medicine, 'Grigore T. Popa', University of Medicine and Pharmacy, Iasi 700115;

${ }^{9}$ Department of Morphological and Functional Sciences, Faculty of Medicine,

Dunarea de Jos University, Galati 050094, Romania; ${ }^{10}$ Department of Forensic Medicine and Toxicology, Aristotle University of Thessaloniki, Thessaloniki 54634, Greece

Received January 24, 2021; Accepted March 19, 2021

DOI: $10.3892 /$ etm.2021.10101

\begin{abstract}
Schizophrenia is a severe brain disorder characterized by certain types of delusion, hallucination and thought disorder. Studies have revealed impaired synaptic plasticity and reduced gamma-aminobutyric acid levels of the visual cortex in patients with schizophrenia. While previous work established a critical role for interneurons and cortical connectivity in the generation of hallucinations, the present study set out to examine the morphology of pyramidal cells and interneurons from layers 3 and 4 in the primary visual cortex from schizophrenic brains and to identify any dendritic and spinal alterations in comparison to normal control brains. The morphological and morphometric changes of the pyramidal cells and the interneurons of the visual cortices of 10 brains obtained from patients with schizophrenia, in comparison to 10 age-matched controls, were studied using the Golgi method and $3 \mathrm{D}$ neuronal reconstruction techniques. Analysis using the Golgi impregnation technique revealed a significant loss of distal dendritic segments, tortuous branches and varicosities and an overall restriction of the dendritic field in the brains of schizophrenic patients in both pyramidal cells and in
\end{abstract}

Correspondence to: Dr Alin-Constantin Iordache or Dr Romeo Dobrin, Faculty of Medicine, 'Grigore T. Popa', University of Medicine and Pharmacy, 16 Strada Universitatii, Iasi 700115, Romania E-mail: aliniordache@yahoo.com

E-mail: romeodobrin2002@gmail.com

Key words: visual cortex, Golgi method, schizophrenia, 3D neuronal reconstruction, pyramidal neurons, aspiny stellate neurons aspiny interneurons. The present results may explain certain clinical phenomena associated with the visual cortex usually encountered in schizophrenia.

\section{Introduction}

Schizophrenia is a severe brain disorder characterized by certain types of delusion, hallucination and thought disorder $(1,2)$. In addition to these aforementioned symptoms that may be associated with enhanced brain activity, schizophrenic patients develop additional symptoms of inhibition, including avolition, alogia and affective flattening (2). Macroscopically, schizophrenic brains exhibited enlargement of the ventricles and an overall reduction in the temporal volume, while microscopical examination of the brain revealed synaptic and spinal alterations, as well as gliosis, in various brain areas, including hippocampal formation and the prefrontal and the entorhinal cortices (3-9). Additional studies have revealed increasing neuronal packaging density, as well as decreased neuropil and smaller cell somata of the pyramidal neurons in layer 3 in different brain areas, including the primary and association auditory cortices, in schizophrenia (9-12). Dendritic spines perform a crucial role in regulating neuronal excitability while receiving the vast majority of excitatory synapses in the cortex $(13,14)$. Deficits in spines are related to impairments in the working memory, attention, sensory-motor processing and sociability (15-17). Spine density has been reported to be significantly reduced in neurons of the auditory cortex (12) and the basilar dendrites of deep layer 3 pyramidal neurons (10), but did not differ for pyramidal neurons in the superficial layer 3 or layers 5 and 6 of area $46(10,18)$. The spinal changes are thought to arise during development and are probably related to disturbances of the mechanisms underlying the formation and maintenance of spines. 
Visual hallucinations are the second most common type of hallucinations in schizophrenia (2). Previous studies demonstrated a critical role for interneurons and cortical connectivity in the generation of hallucinations $(19,20)$. At the same time, studies on the visual cortex of schizophrenic brains have revealed impaired synaptic plasticity and reduced gamma-aminobutyric acid (GABA) levels (21-23).

In the present study, the morphology of the pyramidal cells and interneurons in the visual cortex from brains of schizophrenic patients were examined. It was attempted to describe any possible dendritic and spinal alterations compared to normal control brains.

\section{Patients and methods}

Subjects. Brain samples were obtained from 10 neurologically normal individuals with no history of neurological or psychiatric illness, and 10 patients with schizophrenia, between January 2010 to December 2014 from the Department of Forensic Medicine and Toxicology, at the Aristotle University of Thessaloniki, Greece. All of the subjects were aged between

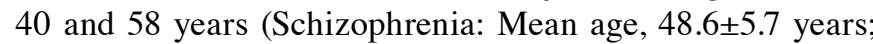
6 males and 4 females; Controls: Mean age, $46.3 \pm 4.97$ years; 7 males and 3 females) and died from heart attack. The average autolysis time for all subjects was $12 \pm 4 \mathrm{~h}$. After their excision from the skull, all brains were immersed in $10 \%$ neutral buffered formalin for at least 25 days. All possible information on each subject regarding their previous physical and illness history was obtained from autopsy reports and medical records. The mean duration of the disease was $21 \pm 7$ years and they had all been prescribed antipsychotic medication. Written informed consent regarding the use of the tissue for research purposes was obtained from the relatives of each of the deceased. The present study was performed according to the legislation of the Greek Democracy (v.2,472/1997, 2,819/2000, 2,915/2001, 3,235/2004 and 3,471/2006) and the Committee for Research Deontology Principles of the Aristotle University of Thessaloniki (24). The ethical approval number was 23/4/4521/2018. The brains were macroscopically and microscopically examined by an independent neuropathologist and did not exhibit any trauma, oedema or other pathology. Independent psychiatrists based at the Psychiatric Hospital of Thessaloniki, made the diagnosis of schizophrenia based on the criteria of the Diagnostic and Statistical Manual of Mental Disorders Text Revision 5. All of the patients exhibited visual hallucinations in their disease history.

Tissue selection and processing. A tissue block measuring $10 \times 5 \times 20 \mathrm{~mm}$ was excised from the primary visual cortex or V1 area (calcarine sulcus) (25) (Fig. 1A). The primary visual cortex may be easily recognized by a band of myelinated axons that run parallel to the surface (line of Gennari; Fig. 1B). The tissue blocks were coded to prevent experimental bias and were processed with the Golgi method and subjected to Nissl staining (26).

Cell selection criteria. Two neuronal types were selected for the present study; the first one corresponds to the third cortical layer's pyramidal neurons and the second to the inhibitory aspiny stellate interneurons of the visual cortex. All neurons chosen for the study were uniformly stained, there was no precipitated debris around them and a good contrast between them and background were present (27).

Golgi method. For silver impregnation, the specimens were immediately immersed in a dilution of potassium dichromate ( $7 \mathrm{~g}$ of potassium dichromate and $20 \mathrm{ml}$ of formaldehyde solution $37 \%$ in $300 \mathrm{ml}$ of tap water) at room temperature. They remained in that solution for one week and were then immersed in an aqueous solution of $1 \%$ silver nitrate, where they remained for one more week at a temperature of $15^{\circ} \mathrm{C}$.

After fixation, the specimens were immersed in paraffin and cut into thick sections $\sim 120 \mu \mathrm{m}$ thick, as neuronal fields can be seen at their whole thickness at $\sim 120 \mu \mathrm{m}$ (25), using a Reichert slicing microtome. A total of 5 randomly selected sections were obtained, with a $480 \mu \mathrm{m}$ distance between each sample. All of the specimens were examined with an Axiostar Plus bright field microscope (Zeiss AG).

Nissl staining. Adjacent sections were cut at a thickness of $20 \mu \mathrm{m}$ and used for Nissl staining to evaluate the neuronal population and define the depth of cortical layers and measure the thickness of the cortex (25).

Neuronal tracing and dendritic quantification. For each one of the 20 brains, 50 pyramidal cells and 50 interneurons were selected. The neurons were then analyzed based on the method described in a previous study by our group (26).

Dendritic measures and Sholl analysis. For the morphometric estimation, soma size, total dendritic length, cell contraction, dendritic field asymmetry, the total number of dendritic segments and bifurcations, and the length and number of dendritic segments per order were measured. Furthermore, the tracings were quantitatively analyzed with Fiji software (version 2017; Fiji) and the Simple Neurite Tracer plugin based on Sholl's method of concentric spheres $(28,29)$. Concentric spheres were drawn at intervals of $10 \mu \mathrm{m}$ centred on the cell bodies and dendritic intersections within each sphere were counted (25).

Spine counts. The dendritic spine density was measured in 360 images, which were taken at a magnification of x1,000. Two different investigators (FP and SC) independently counted visible spines on three random segments of the dendritic tree of 20-30 $\mu \mathrm{m}$ in length, the first one being on a first-order dendrite, the second on a second-order dendrite and the third on a tertiary branch (30).

Statistical analysis. Statistical analysis was performed using Student's t-test based on 320 cells in R Studio (v. 4.04). To make sure that the autolysis time did not affect dendritic measurements, two-tailed Pearson product correlation analyses were performed between all dependent measures and autolysis time (31). $\mathrm{P}<0.05$ was considered to indicate a statistically significant difference.

\section{Results}

Dendritic changes of pyramidal neurons. Analysis with the Golgi impregnation technique revealed a significant loss 

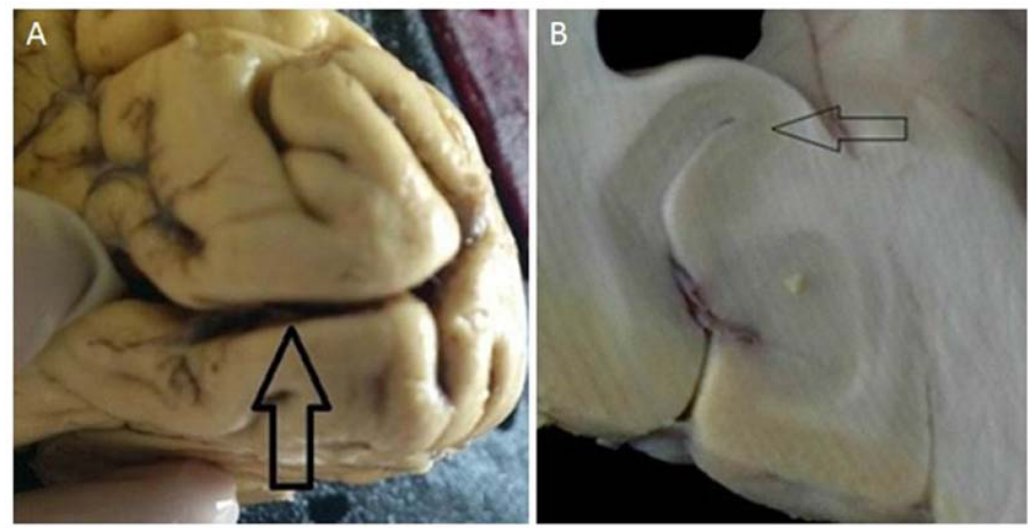

Figure 1. (A) The primary visual cortex is located in and around the calcarine fissure in the occipital lobe (arrow). Occipital lobe sagittal view demonstrating the calcarine fissure. (B) It may be easily recognized by a white band of myelinated axons that run parallel to the surface (line of Gennari; arrow).

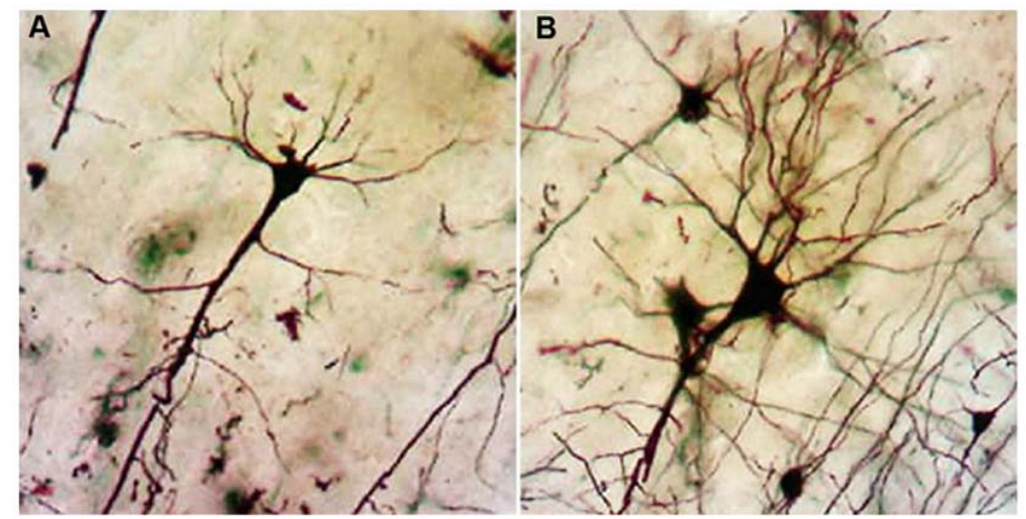

Figure 2. Representative images of pyramidal neurons impregnated with the Golgi method, from (A) a schizophrenic brain and (B) a normal control (Golgi method; magnification, $\mathrm{x} 100$ ).

A

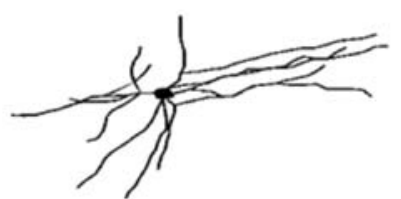

C

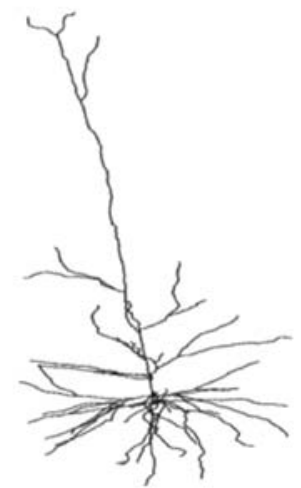

B

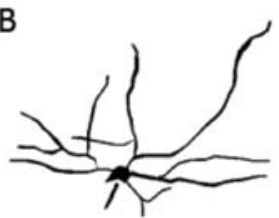

D

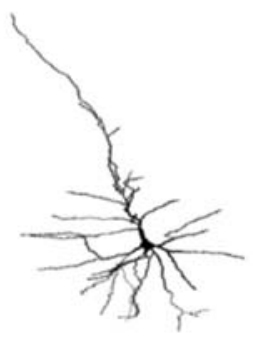

Figure 3. Schematic representation based on neuronal tracings of (A) aspiny in normal controls, (B) aspiny in schizophrenic brains, (C) pyramidal neurons in normal controls and (D) pyramidal neurons in schizophrenic brains showing markedly decreased dendritic arborizations in each cell type in Schizophrenia.

of distal dendritic segments, tortuous branches and varicosities and an overall restriction of the dendritic field in

the schizophrenic brains compared to the normal brains (Fig. 2A and B).

In the brains of schizophrenic subjects, the dendritic field's total length was significantly decreased as compared with that of normal subjects (Figs. 3A-D and 4A). A severe loss of distal dendritic branches (quaternary) (Fig. 4B), and a decrease in the number of terminal branches (Fig. 4C) and dendritic bifurcations were also noted (Fig. 4D).

Compared to the normal controls, the branching ratio was reduced in the schizophrenic group, and the average branch length (Fig. 5A) and the maximum branching order were likewise affected (Fig. 5B). As presented in Fig. 6, Sholl analysis indicated a restriction of the dendritic field due to the loss of distal branches, although the proximal ones in the pyramidal cells remained intact (Fig. 6A). A small amount of degenerated pyramidal neurons was also noted in the schizophrenic brains, and none were identified in the control group (Fig. 7).

Interneurons. Aspiny stellate interneurons of the visual cortex from the schizophrenic brains exhibited a significant decrease of the total dendritic length (Figs. 8A and B and 9A), severe loss of dendritic branches (Fig. 9B) and a substantial reduction of the number of terminal dendritic branches (Fig. 9C). The branching ratio was grossly reduced, and the average branch length and the maximum branch order were significantly 
A

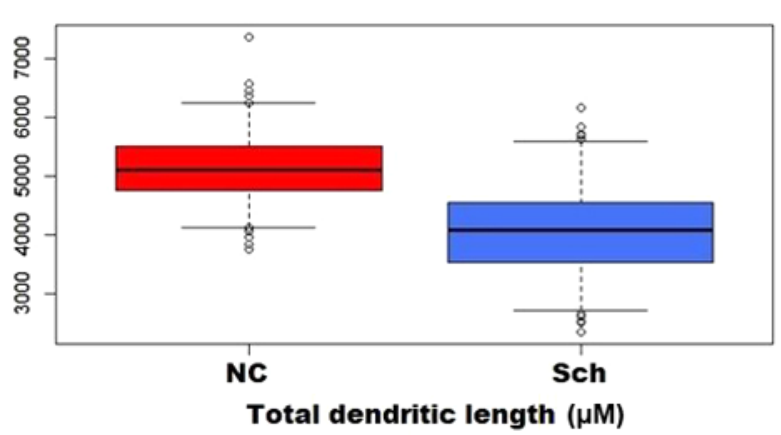

C

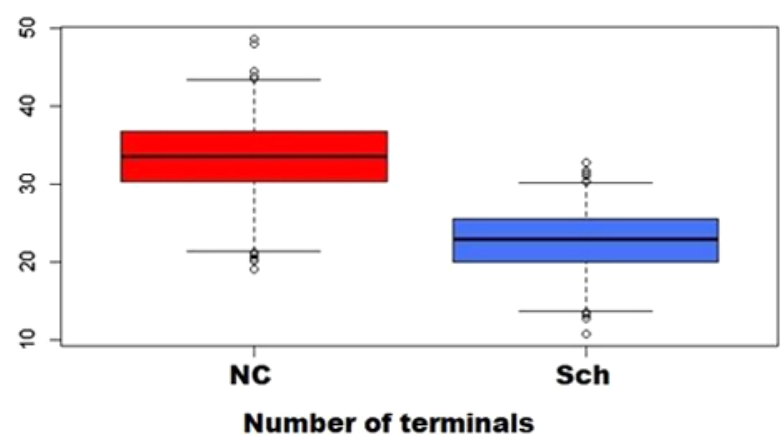

B

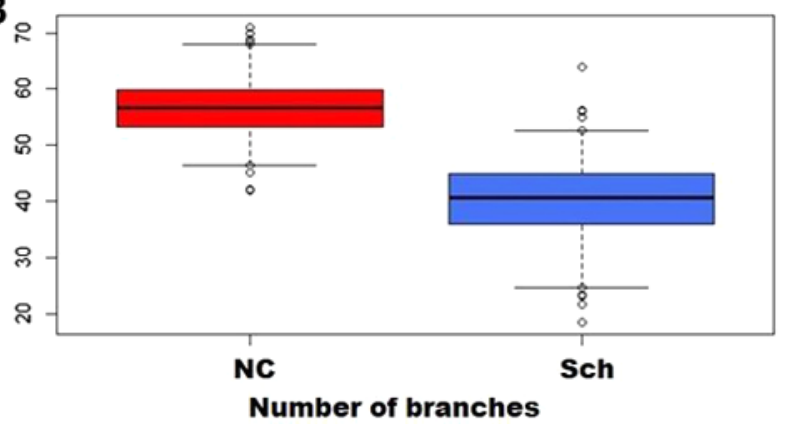

D

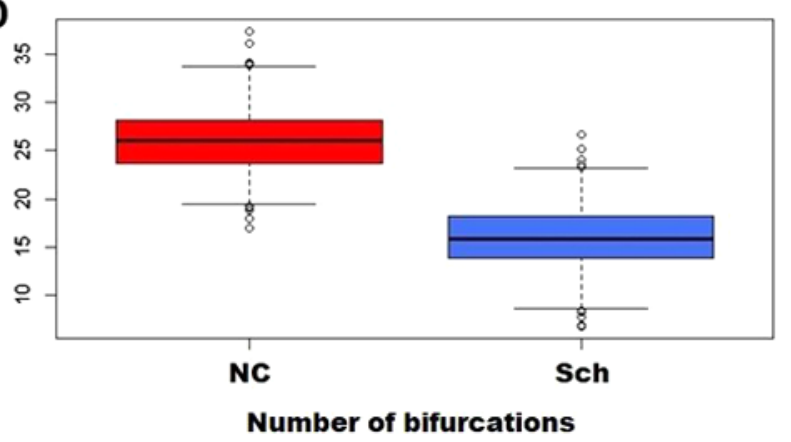

Figure 4. Comparison of $(\mathrm{A})$ total dendritic length $(\mathrm{P}=0.0002),(\mathrm{B})$ number of dendritic branches $(\mathrm{P}=0.0032),(\mathrm{C})$ number of terminals $(\mathrm{P}=0.00001)$ and (D) bifurcations $(\mathrm{P}=0.0001)$ of the pyramidal cells from $\mathrm{NC}$ and schizophrenic brains. Boxplots represent skewness and error bars indicate the standard deviation. NC, normal controls; Sch, schizophrenia group.

A

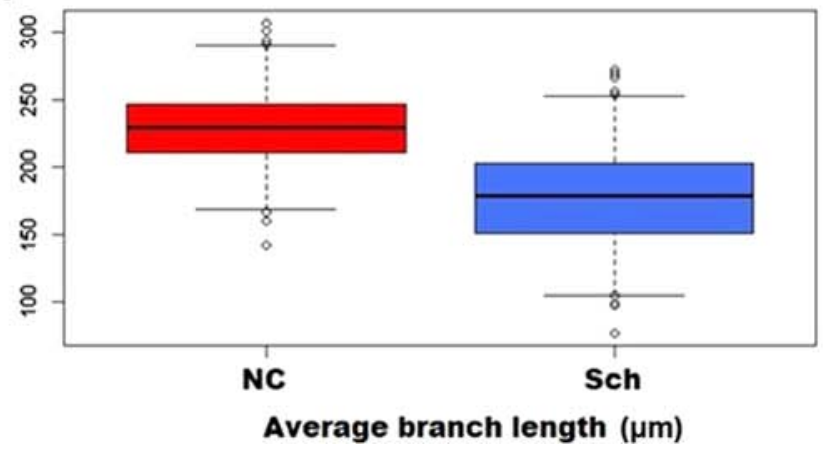

B

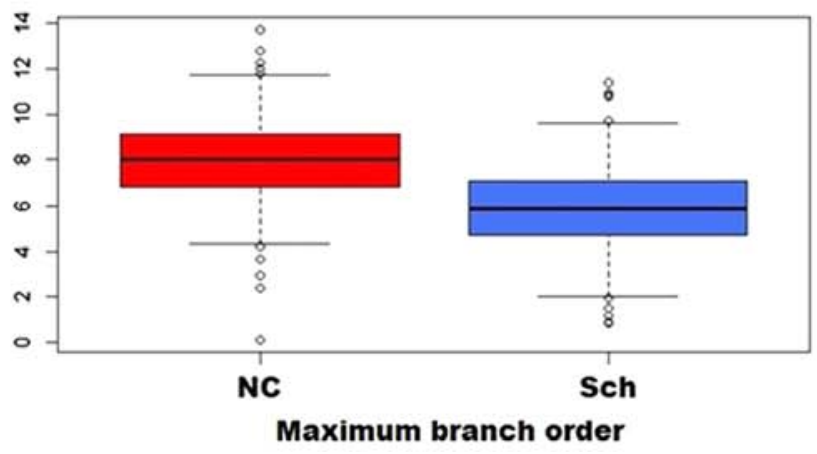

Figure 5. Comparison of $(\mathrm{A})$ average branch length $(\mathrm{P}=0.00049)$ and $(\mathrm{B})$ branch order $(\mathrm{P}=0.0001)$ of the pyramidal cells from NC and schizophrenic brains Boxplots represent skewness and error bars indicate the standard deviation. NC, normal controls; Sch, schizophrenia group.

affected (Fig. 10A and B). Sholl analysis of interneurons indicated extensive loss of distal dendritic branches and decline of the dendritic field density at a distance $>100 \mu \mathrm{m}$ from the cell soma (Fig. 6B). The number of bifurcations was markedly lower in schizophrenic brains compared with controls (Fig. 9D).

Spinal changes. Pyramidal neurons exhibited a significant decrease in spinal density, affecting mainly the distal dendritic segments, while dystrophic and giant spines were also observed (Figs. 11 and 12).

Cortical thickness. The thickness of the primary visual cortex measured in Nissl preparations was significantly different between the groups of the study (Schizophrenia,

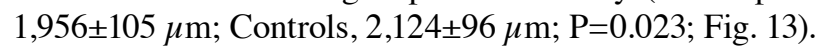

\section{Discussion}

There remains a lack of consensus or set of quantified patient characteristics in regards to Schizophrenia and it has remained an enigma to neuropathologists (32). Accumulating evidence from macroscopic and microscopic pathology has been provided in the last 20 years. The main macroscopic findings include a decrease in brain weight (33-35), brain length (36) and volume of the cerebral hemispheres (37). An additional enlargement of the lateral ventricles $(36,37)$, changes to limbic structures (38), reduced size of temporal lobe structures (39-41), decreased thalamic volume $(34,42)$ and enlarged basal ganglia (43) have also been described. Certain findings regarding synaptic and spinal pathology, cell orientation, neuronal density, neuronal size, protein expression and neurotransmitter deficits have also been consistently reported by numerous studies (6). 

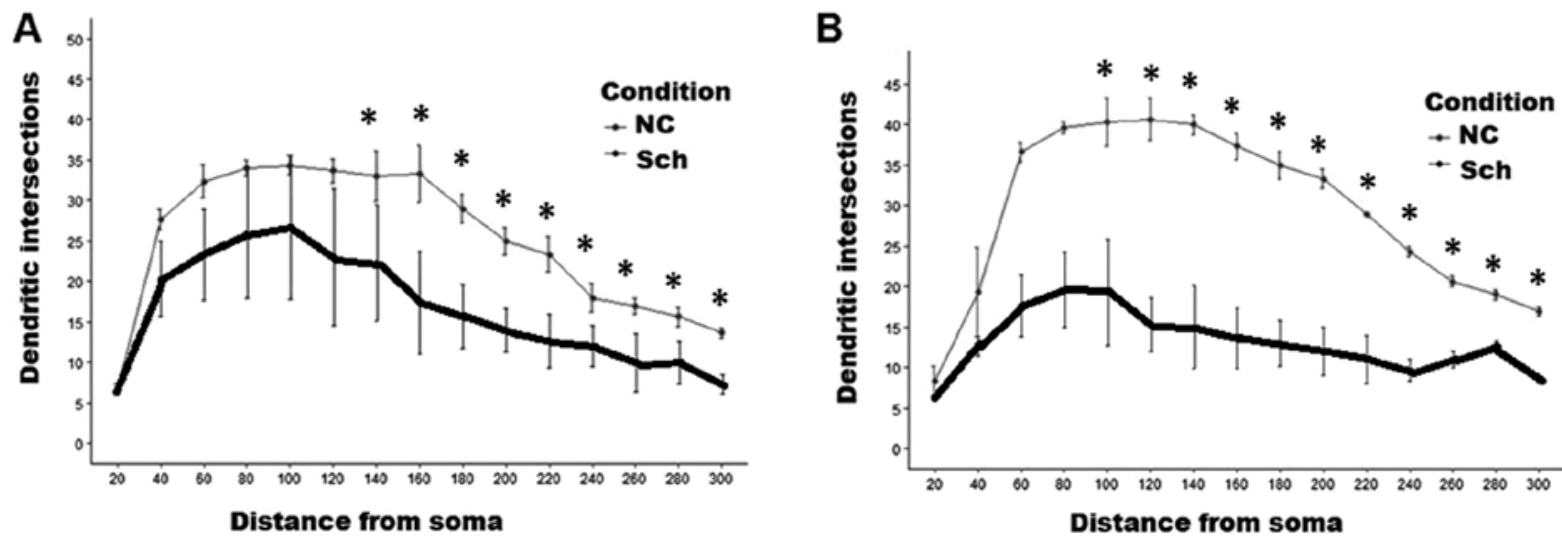

Figure 6. Sholl analysis of (A) the pyramidal cells and (B) interneurons of the visual cortex from NC and schizophrenic brains (bold line). Statistical significance was identified for distances $>120 \mu \mathrm{m}$ for pyramidal neurons and $>100 \mu \mathrm{m}$ for stellate neurons ${ }^{*} \mathrm{P}<0.05$ vs. the NC group. NC, normal controls; Sch, schizophrenia group.

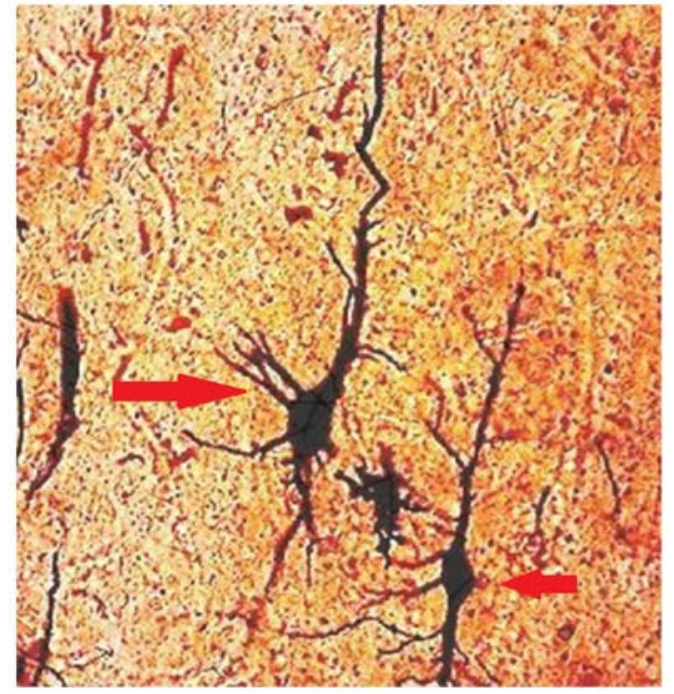

Figure 7. In schizophrenic brains, certain degenerated pyramidal neurons were noted (red arrows). No degenerated neurons were identified in the controls (Golgi method; magnification, x100).

The majority of existing studies are focused on hippocampal formation, the temporal lobe, prefrontal cortex and basal ganglia. To the best of our knowledge, no previous study has reported on the morphological changes of the pyramidal and stellate neurons of the occipital lobe. In 1998, Garey et al (44) reported decreased spinal density on the pyramidal cells of lamina III from Brodmann areas 11 and 38 observed on Golgi staining, and in the same year, Woo et al (45) indicated a selective decrease of terminal branches in brodmann areas 9 and 46 chandelier neurons.

In 1996, Roberts et al (46) revealed changes of the dendritic spines at the striatum, and in the same year, Uranova et al (47) described certain changes in the postsynaptic density of axo-spinous synapses.

In addition, Dorph-Petersen et al (22) reported significantly decreased neuronal volume with no significant reduction of the neuronal density in the primary visual cortex of schizophrenic brains. These results were confirmed by neuroimaging studies using voxel-based morphometry, which reported a significant reduction in the occipital lobe's overall
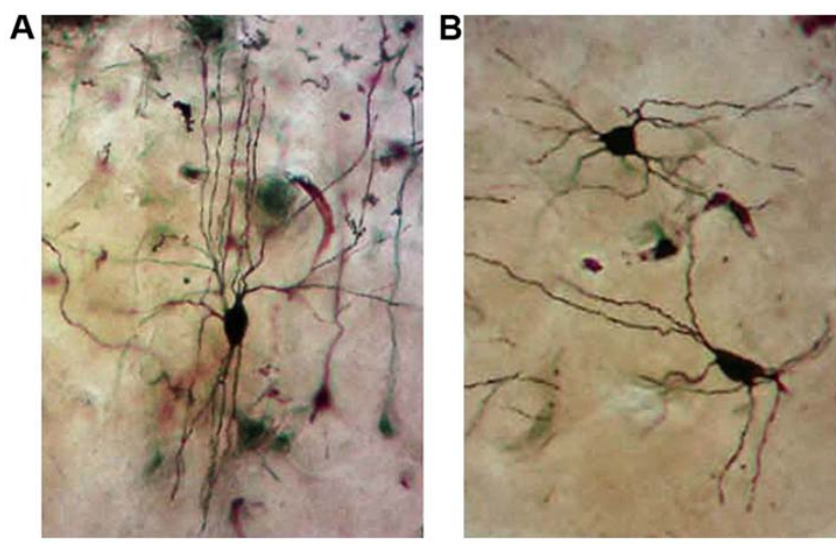

Figure 8. Representative examples of aspiny interneurons impregnated with the Golgi method from (A) normal controls and (B) schizophrenic brains (Golgi method; magnification, x100).

volume with a decrease in grey matter in schizophrenic patients (48-52).

In the present study, no significant changes in the neuronal density of the primary visual cortex were obtained, but the overall thickness of the primary visual cortex was substantially decreased in schizophrenic brains, corroborating the findings of the earlier study by Dorph-Petersen et al (22). Golgi silver staining and 3D reconstruction of neurons revealed several morphological changes on both cortical aspiny interneurons and pyramidal cells. The total neuronal volume was decreased in both populations. The aspiny interneurons exhibited a severe restriction of their dendritic field areas, along with a loss of distal and terminal dendritic branches. Pyramidal neurons from lamina III similarly exhibited a significant loss of terminal branches and substantially lower dendritic spines, mainly on the distal branches.

Regarding the clinical significance of the present results, visual hallucinations are amongst the most common symptoms associated with increased brain activity in patients with schizophrenia (48). They have been correlated to GABA deficits and functional impairment of cortical interneurons, as well as a disturbance of cortico-thalamic or intracortical connections (19). Furthermore, studies have revealed certain functional deficits of the visual cortex in schizophrenic 

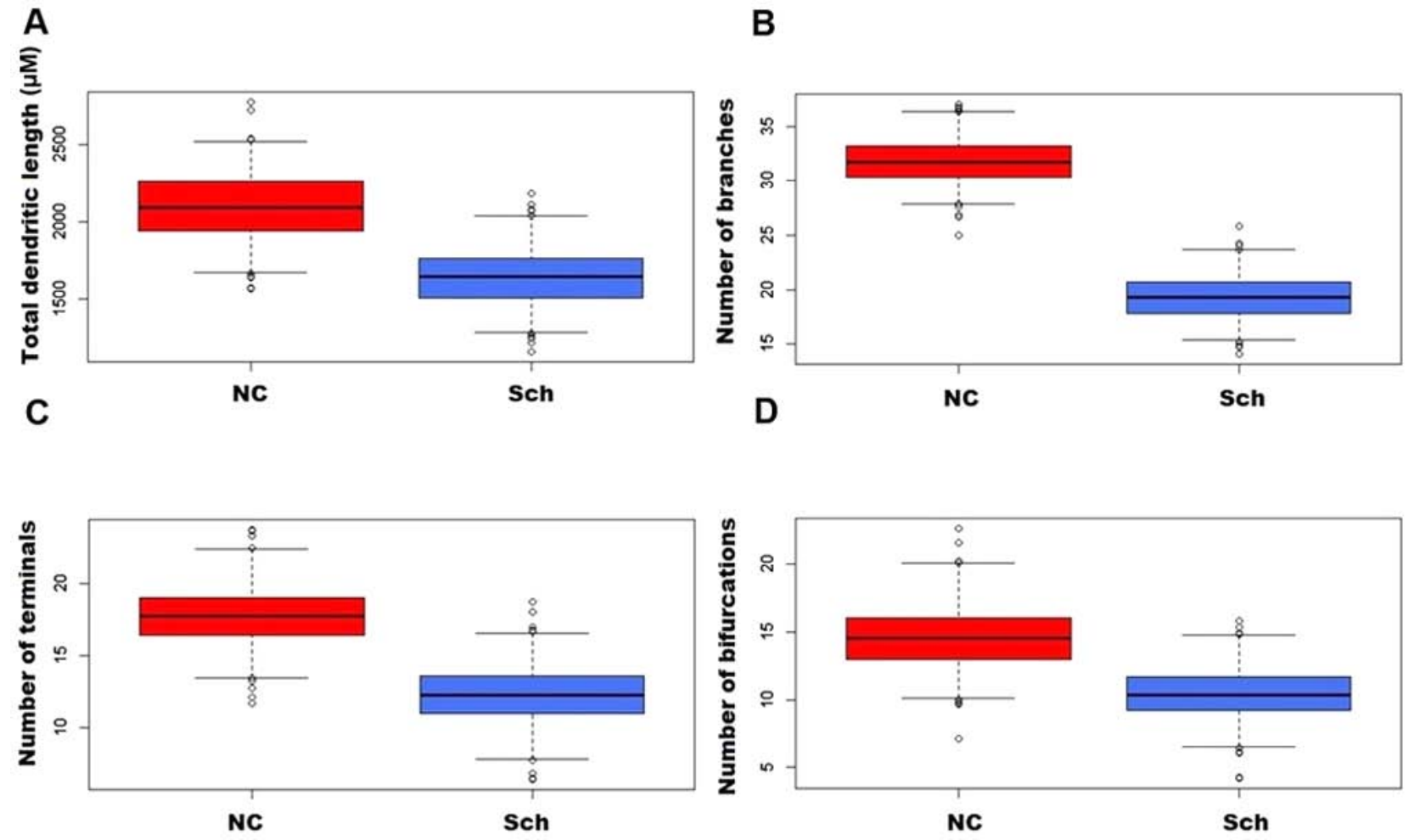

Figure 9. Comparison of (A) total dendritic length $(\mathrm{P}=0.0049)$, (B) number of branches $(\mathrm{P}=0.003)$, (C) numbers of terminals $(\mathrm{P}=0.00021)$ and (D) bifurcations $(\mathrm{P}=0.0001)$ of interneurons from NC and schizophrenic brains. Boxplots represent skewness and error bars indicate the standard deviation. NC, normal controls; Sch, schizophrenia group.

A

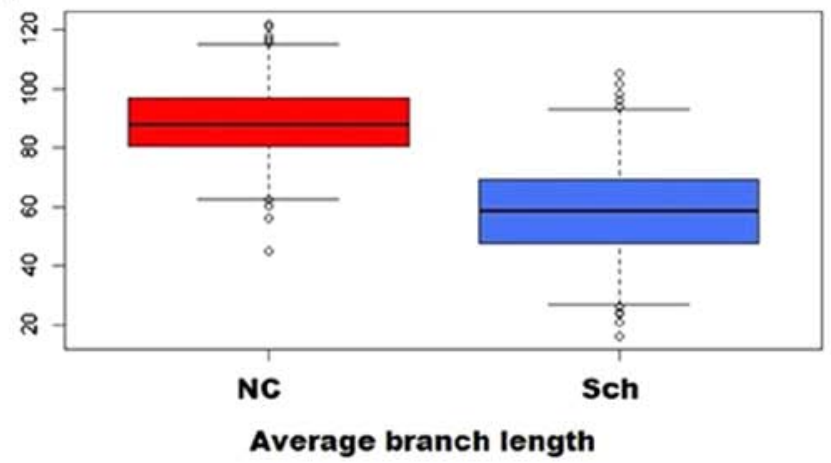

B

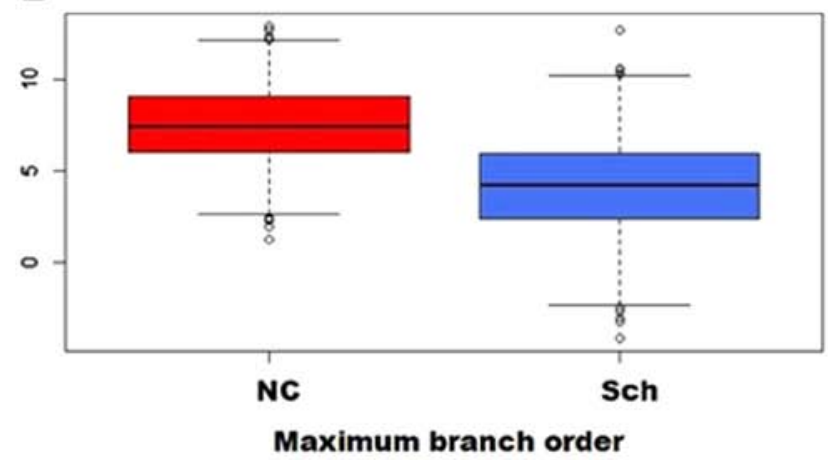

Figure 10. Comparison of (A) average branch length in $\mu \mathrm{m}(\mathrm{P}=0.001)$ and $(\mathrm{B})$ branch order $(\mathrm{P}=0.001)$ of interneurons from NC and schizophrenic brains. Boxplots represent skewness and error bars indicate the standard deviation. NC, normal controls; Sch, schizophrenia group.

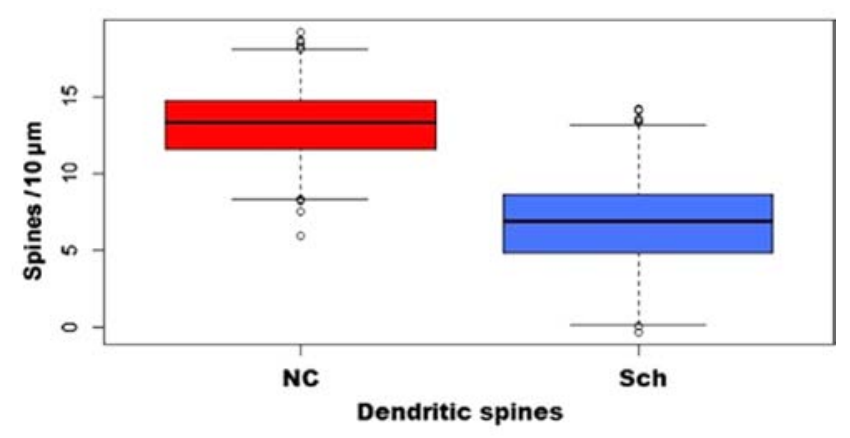

Figure 11. Spinal density of the pyramidal neurons of the visual cortex from $\mathrm{NC}$ and schizophrenic brains $(\mathrm{P}=0.0034)$. Boxplots represent skewness and error bars indicate the standard deviation. NC, normal controls; Sch, schizophrenia group. patients, including early-stage visual processing, contrast sensitivity abnormalities, surround suppression and motor processing disturbance $(53,54)$. Lamina III pyramidal neurons contribute to reception, elaboration and transmission of the visual information to other cortical areas, while the aspiny interneurons provide inhibitory control and modulate the synchronized oscillations (55). Both neuronal populations are critical for the integrity of the cortico-thalamic and intracortical circuits. The loss of dendrites and dendritic spines of both pyramidal cells and interneurons leads to a substantial decrease of the synaptic contacts and a significant impairment of the pyramidal-interneuronal connectivity, as well as of the connections of the cells of the visual cortex with the neurons of other cortical and subcortical areas, which may be 
A

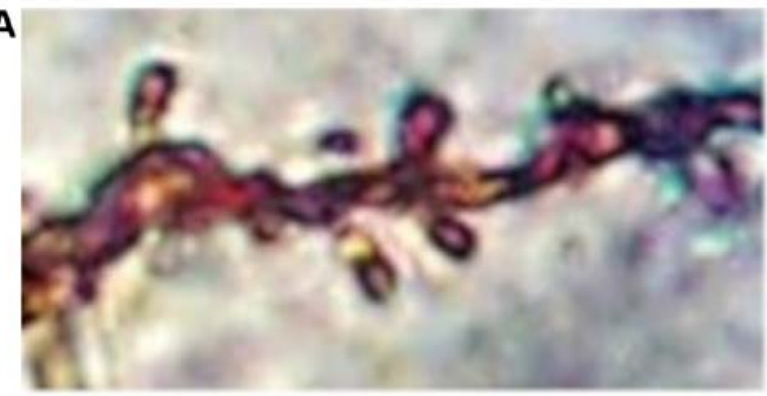

B

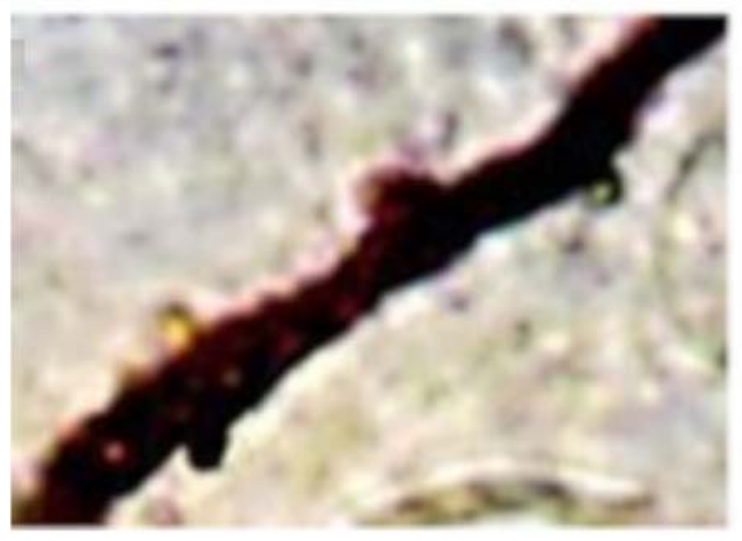

C

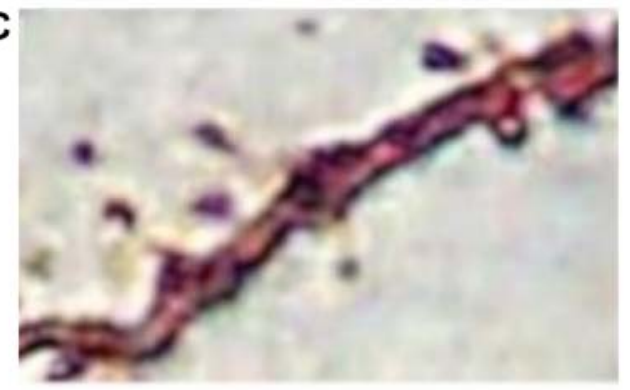

D

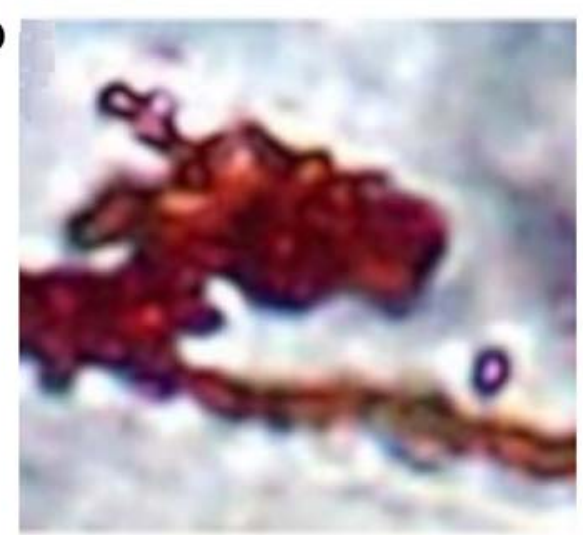

Figure 12. Representative examples of dendritic segments from (A) normal controls and (B-D) schizophrenic brains indicating (B) significant loss of dendritic spines, (C) patchy areas devoid of spines and (D) dystrophic spines (Golgi method; magnification, x1,000).
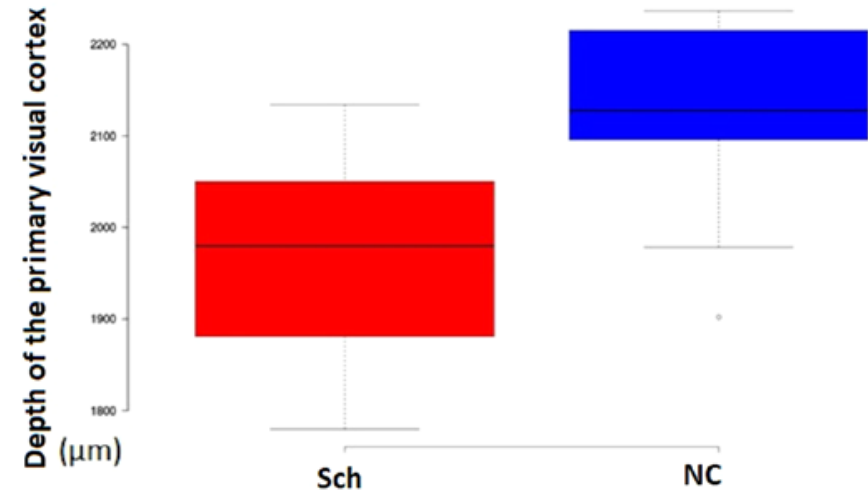

Figure 13. The depth of the primary visual cortex in patients with Sch and NCs. Boxplots represent 1st and 3rd quartiles, whiskers represent lower and higher values. Sch, Schizophrenia; NC, control.

implicated in the modulation of the visual information $(30,55)$. Although other cortical areas beyond the primary visual cortex are related to the production of visual hallucinations, the interruption of connectivity of the primary visual cortex with secondary visual, temporal and parietal areas may have a crucial role in the pathophysiology of visual hallucinations and other functional deficits of the visual cortex in schizophrenia.

To the best of our knowledge, the present study was the first to describe the morphological alterations in pyramidal and spinal stellate neurons on the primary visual cortex in patients with schizophrenia. The results may provide novel insights into the brain changes exhibited by patients with schizophrenia. It may be concluded that the present observations may be related to certain clinical phenomena associated with the visual cortex usually encountered in schizophrenia.

\section{Acknowledgements}

Not applicable.

\section{Funding}

No funding was received.

\section{Availability of data and materials}

The datasets used and/or analyzed during the current study are available from the corresponding author on reasonable request.

\section{Authors' contributions}

IM prepared the manuscript and supervised the data collection and analysis. FP, SC, EK and DK collected and analyzed the data, and prepared the specimens. AC, ACI, RD and CT prepared the manuscript and analyzed the data. SN, VC and SB made substantial contributions to conception and design, acquisition of data and analysis and interpretation of data. IM and SB confirm the authenticity of all the raw data. All authors have read and approved the final manuscript.

\section{Ethics approval and consent to participate}

The present study was performed according to the legislation of the Greek Democracy (v.2,472/1997, 2,819/2000, 2,915/2001, 3,235/2004 and 3,471/2006) and the Committee for Research Deontology Principles of the Aristotle University of Thessaloniki (24) (approval no. 23/4/4521/2018). Written informed consent was obtained from relatives. 


\section{Patient consent for publication}

For each of the patients and controls, and written informed consent was obtained from their relatives and power of attorneys regarding the publication of data and associated images.

\section{Competing interests}

The authors declare that they have no competing interests.

\section{References}

1. McKenna K Gordon C and Rapoport J: Childhood-onset schizophrenia: Timely neurobiological research. J Am Acad Child Adolesc Psychiatry 33: 771-781, 1994.

2. Andreasen N: Symptoms, signs, and diagnosis of schizophrenia. Lancet 346: 477-481, 1995.

3. Flaum M, Arndt S and Andreasen NC: The role of gender in studies of ventricle enlargement in schizophrenia: A predominantly male effect. Am J Psychiatry 147: 1327-1332, 1990.

4. Jellinger K: Neuromorphological Background of Pathochemical Studies in Major Psychoses. 1st Edition, Springer, Berlin, pp1-23, 1985.

5. Johnstone EC, Bruton CJ, Crow TJ, Frith CD and Owens DG: Clinical correlates of postmortem brain changes in schizophrenia: Decreased brain weight and length correlate with indices of early impairment. J Neurol Neurosurg Psychiatry 57: 474-479, 1994

6. Harrison PJ: The neuropathology of schizophrenia. A critical review of the data and their interpretation. Brain 122: 593-624, 1999.

7. Haug JO: Pneumoencephalographic evidence of brain atrophy in acute and chronic schizophrenic patients. Acta Psychiatr Scand 66: 374-383, 1982.

8. Porter RH, Eastwood SL and Harrison PJ: Distribution of kainite receptor subunit mRNAs in human hippocampus, neocortex and cerebellum, and bilateral reduction of hippocampal GluR6 and KA2 transcripts in schizophrenia. Brain Res 751: 217-231, 1997.

9. Rajkowska G, Selemon LD and Goldman-Rakic PS: Neuronal and glial somal size in the prefrontal cortex: A postmortem morphometric study of schizophrenia and Huntington disease. Arch Gen Psychiatry 55: 215-224, 1998.

10. Glantz LA and Lewis DA: Decreased dendritic spine density on prefrontal cortical pyramidal neurons in schizophrenia. Arch Gen Psychiatry 57: 65-73, 2000.

11. Pierri JN, Volk CL, Auh S, Sampson A and Lewis DA: Decreased somal size of deep layer 3 pyramidal neurons in the prefrontal cortex of subjects with schizophrenia. Arch Gen Psychiatry 58 466-473, 2001

12. Sweet RA,Pierri JN, Auh S, Sampson AR and Lewis DA: Reduced pyramidal cell somal volume in auditory association cortex of subjects with schizophrenia. Neuropsychopharmacology 28 : 599-609, 2003

13. DeFelipe $\mathrm{J}$ and Fariñas I: The pyramidal neuron of the cerebral cortex: Morphological and chemical characteristics of the synaptic inputs. Prog Neurobiol 39: 563-607, 1992.

14. Wilson CJ: GABAergic inhibition in the neostriatum. Prog Brain Res 160: 91-110, 2007.

15. Liston C, Miller MM, Goldwater DS, Radley JJ, Rocher AB Hof PR, Morrison JH and McEwen BS: Stress-induced alterations in prefrontal cortical dendritic morphology predict selective impairments in perceptual attentional set-shifting. J Neurosci 26: 7870-7874, 2006.

16. Cahill ME,XieZ,Day M,Photowala H,Barbolina MV,Miller CA Weiss C, Radulovic J, Sweatt JD, Disterhoft JF, et al: Kalirin regulates cortical spine morphogenesis and disease-related behavioral phenotypes. Proc Natl Acad Sci USA 106: 13058-13063, 2009.

17. Brennaman LH, Kochlamazashvili G, Stoenica L, Nonneman RJ, Moy SS, Schachner M, Dityatev A and Maness PF: Transgenic mice overexpressing the extracellular domain of NCAM are impaired in working memory and cortical plasticity. Neurobiol Dis 43: 372-378, 2011

18. Kolluri N, Sun Z, Sampson AR and Lewis DA: Lamina-specific reductions in dendritic spine density in the prefrontal cortex of subjects with schizophrenia. Am J Psychiatry 162: 1200-1202, 2005 .
19. Boksa P: On the neurobiology of hallucinations. J Psychiatry Neurosci 34: 260-262, 2009.

20. delaIglesia-VayaM,EscartíMJ,Molina-MateoJ,Martí-BonmatíL, Gadea M, Castellanos FX, Aguilar García-Iturrospe EJ, Robles M, Biswal BB and Sanjuan J: Abnormal synchrony and effective connectivity in patients with schizophrenia and auditory hallucinations. Neuroimage Clin 6: 171-179, 2014.

21. Cavus I, Reinhart RM, Roach BJ, Gueorguieva R, Teyler TJ, Clapp WC, Ford JM, Krystal JH and Mathalon DH: Impaired visual cortical plasticity in schizophrenia. Biol Psychiatry 71: 512-520, 2012

22. Dorph-Petersen KA, Pierri JN, Wu Q, Sampson AR and Lewis DA: Primary visual cortex volume and total neuron number are reduced in schizophrenia. J Comp Neurol 501: 290-301, 2007.

23. Yoon JH, Maddock RJ, Rokem A, Silver MA, Minzenberg MJ, Ragland JD and Carter CS: GABA concentration is reduced in visual cortex in schizophrenia and correlates with orientationspecific surround suppression. J Neurosci 30: 3777-3781, 2010.

24. Research Committee. Research Deontology Principles. 2nd edition, Aristotle University of Thessaloniki, Thessaloniki, pp22-25, 2010.

25. Mavroudis IA, Fotiou DF, Manani MG, Njaou SN, Frangou D, Costa VG and Baloyannis SJ: Dendritic pathology and spinal loss in the visual cortex in Alzheimer's disease a Golgi study in pathology. Int J Neurosci 121: 347-354, 2011.

26. Mavroudis IA, Petrides F, Manani M, Chatzinikolaou F, Ciobica AS, Padurariu M, Kazis D, Njau SN, Costa VG and Baloyannis SJ: Purkinje cells pathology in schizophrenia. A morphometric approach. Rom J Morphol Embryol 58: 419-424, 2017.

27. Jacobs B, Driscoll L and Schall M: Life-span dendritic and spine changes in areas 10 and 18 of human cortex: A quantitative Golgi study. J Comp Neurol 386: 661-680, 1997.

28. Johannes S, Arganda-Carreras I, Frise E, Kaynig V, Longair M, Pietzsch T, Preibisch S, Rueden C, Saalfeld S, Schmid B, et al: Fiji: An open-source platform for biological-image analysis. Nat Methods 9: 676-682, 2012.

29. Sholl DA: The organization of the visual cortex in the cat. J Physiol 124: 23-24, 1954.

30. Anderson K, Bones B, Robinson B, Hass C, Lee H, Ford K, Roberts TA and Jacobs B: The morphology of supragranular pyramidal neurons in the human insular cortex: A quantitative Golgi study. Cerebral Cortex 19: 2131-2144, 2009.

31. PlumF:Prospects for research on schizophrenia.3. Neurophysiology. Neuropathological findings. Neurosci Res Program Bull 10: 384-388, 1972.

32. Brown R, Colter N, Corsellis JA, Crow TJ, Frith CD, Jagoe R, Johnstone EC and Marsh L: Postmortem evidence of structural brain changes in schizophrenia. Differences in brain weight, temporal horn area, and parahippocampal gyrus compared with affective disorder. Arch Gen Psychiatry 43: 36-42, 1986.

33. Pakkenberg B: The volume of the mediodorsal thalamic nucleus in treated and untreated schizophrenics. Schizophr Res 7: 95-100, 1992.

34. Bruton CJ, Crow TJ, Frith CD, Johnstone EC, Owens DG and Roberts GW: Schizophrenia and the brain: A prospective cliniconeuropathological study. Psycholo Med 20: 285-304, 1990.

35. Crow TJ, Ball J, Bloom SR, Brown R, Bruton CJ, Colter N, Frith CD, Johnstone EC, Owens DG and Roberts GW: Schizophrenia as an anomaly of development of cerebral asymmetry. Arch Gen Psychiatry 46: 1145-1150, 1989.

36. Pakkenberg B: Post-mortem study of chronic schizophrenic brains. Br J Psychiatry 151: 744-752, 1987.

37. Bogerts B,Falkai P,Haupts M, Greve B,Ernst S, Tapernon-Franz U and Heinzmann U: Post-mortem volume measurements of limbic system and basal ganglia structures in chronic schizophrenics. Initial results from a new brain collection. Schizophr Res 3: 295-301, 1990

38. Falkai P, Bogerts B and Rozumek M: Limbic pathology in schizophrenia: The entorhinal region-a morphometric study. Biol Psychiatry 24: 515-521, 1998.

39. Falkai $P$ and Bogerts B: Cell loss in the hippocampus of schizophrenics. Eur Arch Psychiatry Neurol Sci 236: 154-161, 1986.

40. Altshuler LL, Casanova MF, Goldberg TE and Kleinman JE: The hippocampus and parahippocampus in schizophrenia, suicide, and control brains. Arch Gen Psychiatry 47: 1029-1034, 1990.

41. Vogeley K, Hobson T, Schneider-Axmann T, Honer WG, Bogerts B and Falkai P: Compartmental volumetry of the superior temporal gyrus reveals sex differences in schizophrenia-a post-mortem study. Schizophr Res 31: 83-87, 1998. 
42. Danos P, Baumann B, Bernstein HG, Franz M, Stauch R, Northoff G, Krell D, Falkai P and Bogerts B: Schizophrenia and anteroventral thalamic nucleus: Selective decrease of parvalbumin-immunoreactive thalamocortical projection neurons. Psychiatry Res 82: 1-10, 1989.

43. Heckers S, Heinsen $\mathrm{H}$ and Heinsen YC: Limbic structures and lateral ventricle in schizophrenia: A quantitative post-mortem study. Arch Gen Psychiatry 47: 1016-1022, 1991.

44. Garey LJ, Ong WY, Patel TS, Kanani M, Davis A, Mortimer AM, Barnes TR and Hirsch S: Reduced dendritic spine density on cerebral cortical pyramidal neurons in schizophrenia. J Neurol Neurosurg Psychiatry 65: 446-453, 1998.

45. Woo TU, Whitehead RE, Melchitzky DS and Lewis DA: A subclass of prefrontal gamma- aminobutyric acid axon terminals are selectively altered in schizophrenia. Proc Natl Acad Sci USA 95: 5341-5346, 1998.

46. Roberts RC, Conley R, Kung L, Peretti FJ and Chute DJ: Reduced striatal spine size in schizophrenia: A post-mortem ultrastructural study. Neuroreport 7: 1214-1218, 1996.

47. Uranova NA, Casanova MF, DeVaughn NM, Orlovskaya DD and Denisov DV: Ultrastructural alterations of synaptic contacts and astrocytes in postmortem caudate nucleus of schizophrenic patients (letter). Schizophr Res 22: 81-83, 1996.

48. Andreasen NC, Flashman L, Flaum M, Arndt S, Swayze V and O'Leary DS: Regional brain abnormalities in schizophrenia measured with magnetic resonance imaging. JAMA 272: 1763-1769, 1994.

49. Bilder RM, Wu H, Bogerts B, Ashtari M, Robinson D and Woerner M: Cerebral volume asymmetries in schizophrenia and mood disorders: A quantitative magnetic resonance imaging study. Int J Psychophysiol 34: 197-205, 1999.
50. Bilder RM, Wu H, Bogerts B, Degreef G, Ashtari M and Alvir JM: Absence of regional hemispheric volume asymmetries in first-episode schizophrenia. Am J Psychiatry 151: 1437-1447, 1994.

51. Goldstein JM, Goodman JM, Seidman LJ, Kennedy DN, Makris $\mathrm{N}$ and Lee $\mathrm{H}$ : Cortical abnormalities in schizophrenia identified by structural magnetic resonance imaging. Arch Gen Psychiatry 56: 537-547, 1999.

52. Zipursky RB, Lim KO, Sullivan EV, Brown BW and Pfefferbaum A: Widespread cerebral gray matter volume deficits in schizophrenia. Arch Gen Psychiatry 49: 195-205, 1992.

53. Butler P, Silverstein S and Dakin S: Visual perception and its impairment in schizophrenia. Biol Psychiatry 64: 40-47, 2008.

54. Slaghuis W: Contrast sensitivity for stationary and drifting spatial frequency gratings in positive and negative-symptom schizophrenia. J Abnorm Psychol 107: 49-62, 1998.

55. Jones KS, Corbin JG and Huntsman MM: Neonatal NMDA receptor blockade disrupts spike timing and glutamatergic synapses in fast spiking interneurons in a NMDA receptor hypofunction model of schizophrenia. PLoS One 9: e109303, 2014.

This work is licensed under a Creative Commons Attribution-NonCommercial-NoDerivatives 4.0 International (CC BY-NC-ND 4.0) License. 